\title{
DERECHO A LA EDUCACIÓN: SOBRE LA CON-FORMACIÓN PARA UNA VIDA CUALIFICADA
}

\author{
Right to educatión: about the con-formación for a qualified life
}

Juan Francisco Lobo Fernández.*

\begin{abstract}
Resumen: A la luz de la movilización estudiantil que se ha venido desarrollando en Chile a partir de mayo de 2011, se reformula la educación como con-formación para una vida cualificada orientada al trato con otros como agentes libres e iguales, a la vez que se propone el derecho social a la educación como un derecho de vida cualificada que demanda mayor intervención del Estado en su satisfacción.
\end{abstract}

Palabras clave: derecho a la educación - virtud - vida cualificada.

Abstract: In the light of the student's strike in 2011, the education is rephrased as conformación for a qualified life towards the treatment with others as free and equal agents, while the social right to education is proposed as a right of qualified life which requires more intervention by the State for it's satisfaction.

Keywords: right to education - virtue - qualified life.

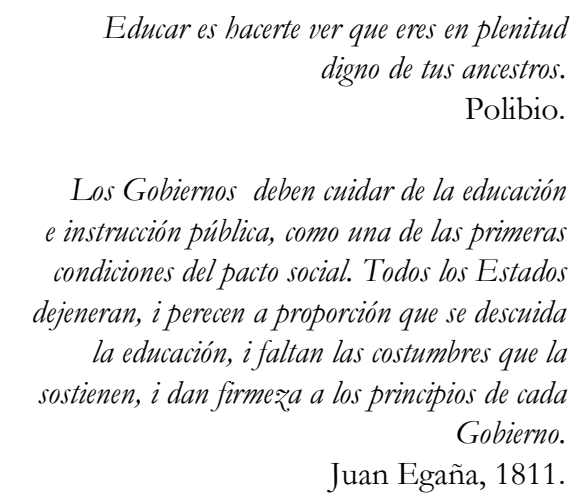

\section{Introducción}

Las palabras de Alexis de Tocqueville, "lo que solemos llamar instituciones necesarias, muchas veces son instituciones a las que nos hemos acostumbrado", reverberan en la movilización estudiantil iniciada en Chile en mayo de 2011, que se prolonga por cerca de dieciocho meses al tiempo en que se escriben estas líneas. El

\footnotetext{
* Egresado de la Facultad de Derecho de la Universidad de Chile. Ayudante ad-honorem de las cátedras de Derecho Internacional de los Derechos Humanos y Teoría General del Derecho. Correo electrónico:juanfranciscolobo@gmail.com
}

Este artículo fue recibido el 1 de agosto de 2012, siendo aprobada su publicación con fecha 25 de enero de 2013. 
sello característico de toda crisis es la ruptura de dicho acostumbramiento, la superación de una actitud inopinada hacia la realidad. Esta vez se trata del cuestionamiento de un modelo educacional configurado a base de una constitución y una ley orgánica constitucional otorgados por un gobierno de facto entre 1980 y 1991.

Lo hasta ahora inconcuso comienza a ser erosionado por diversos argumentos provenientes de distintos sectores sociales, todos los cuales han contribuido a la formación de un robusto debate público en torno a la educación. Es como si la discusión constitucional que no se pudo suscitar entre la ciudadanía a fines de los años setenta por haber estado capturado el foro por el poder de facto, se estuviera produciendo recién ahora.

La presente reflexión pretende ser un aporte más a esa discusión constitucional pendiente. En primer lugar, se abordará la educación como tal, no desde una perspectiva pedagógica ni técnica, sino desde la filosofía política, para desentrañar su significado y valor en una sociedad democrática (2).

En segundo lugar, se analizará el derecho a la educación desde una perspectiva netamente jurídica, en particular en lo referente a su debatida condición de derecho subjetivo, al tiempo que se emprenderá una nueva clasificación tentativa de los derechos fundamentales a efectos de establecer la función del Estado en su satisfacción (3).

Por último, se plasmarán en una sección final las principales conclusiones de la presente reflexión (4).

\section{Sobre la educación}

En su más reciente obra, Carlos Ruiz Schneider acomete un valioso ejercicio de etiología del estado patológico de la enseñanza en Chile.

Su análisis se remonta hasta el nacimiento de la República, época a partir de la cual la educación estuvo destinada a la formación de "buenos ciudadanos" para la incipiente nación. ${ }^{1}$ Lo que esta educación republicana buscaba en especial era formar la virtud cívica de los ciudadanos, tal como la entiende Montesquieu, es decir, como renuncia a uno mismo y amor a las leyes y a la patria en la forma de una preponderancia del interés público sobre el interés particular. Ese amor en que consiste la virtud solo podía ser inculcado mediante la educación. ${ }^{2}$

\footnotetext{
${ }^{1}$ Ruiz, Carlos: De la República al mercado. Ideas educacionales y politica en Chile, Santiago, Chile, LOM, 2010, p. 15.

2 Ibid., p. 15. Montesquieu: Del espiritu de las leyes, Madrid, España: Tecnos, 2000, pp. 28-29.
} 
Pues bien, este desiderátum republicano en la educación pervive todo a lo largo del siglo XIX, aunque adopta diferentes matices entre conservadores y liberales. Sin embargo, el punto de inflexión en la educación se produce tempranamente en el siglo XX, con las propuestas para una educación nacionalista orientada a aumentar la productividad nacional y la competitividad internacional. ${ }^{3}$ Este giro economicista devendrá en la educación orientada al desarrollo económico y a la modernización de la sociedad en la década de los 60 , volcándose finalmente de forma plena hacia el mercado con la irrupción del neoliberalismo en la década de los 80 , lo que se mantuvo durante los gobiernos democráticos. ${ }^{4}$

El punto de inflexión de este sendero que condujo de la República al mercado, la propuesta nacionalista para una educación económica, estuvo influenciado por el filósofo norteamericano John Dewey. Este sostiene que la teoría de la evolución de Darwin puede ser extrapolada a la filosofía política para proponer que el telos de toda sociedad es el "desarrollo", y por tanto a este debe propender la educación. ${ }^{5}$

Precisamente en contra del modelo educativo económico orientado hacia el desarrollo arremete Hannah Arendt en un ensayo publicado a comienzos de la década de 1960, The crisis in education. La educación económica, instalada en EE.UU. al tiempo en que Arendt acomete su crítica, propugna el desplazamiento del aprendizaje por el hacer, y del conocimiento por la habilidad. ${ }^{6}$ Contra la corriente, Arendt defiende la idea de que la esencia de la educación estriba en la "natalidad". 7

La natalidad es para Arendt una de las múltiples condiciones que contribuyen a determinar lo que en conjunto designa como "la condición humana". Entre otras, destacan las tres condiciones correlativas a cada una de las tres dimensiones de la denominada vita activa, es decir: la "vida" como condición de la "labor", la "mundanidad" como condición del "trabajo", y la "pluralidad" como condición de la "acción".?

En breve, labor es el proceso biológico del cuerpo humano (zoé para los griegos, por oposición a la vida buena/cualificada o bios), cuyo sujeto es el animal laborans. Trabajo es la fabricación manual del artificio humano, cuyo sujeto es el homo faber. Acción, por último, es tomar la iniciativa, comenzar, poner algo en

\footnotetext{
${ }^{3}$ Ruiz, Carlos: op. cit. (nota 1) pp. 20; 24; 31; 64.

${ }^{4}$ Ibid., pp. 83; 102; 138.

${ }^{5}$ Horwitz, Robert. John Dewey. En: Strauss, Leo y Cropsey, Joseph (comp.): Historia de la filosofía política, $3^{\mathrm{a}}$ ed., México D.F., México, FCE, 2006, pp. 805-806.

6 Arendt, Hannah: "The crisis in education". En su: Between past and future. Eight exercises in political thought, Nueva York, Estados Unidos, The Viking Press, 1961, pp. 178; 182-183.

${ }^{7}$ Ibid., p. 174.

${ }^{8}$ Arendt, Hannah: La condición bumana, Buenos Aires, Paidós, 2005, p. 25.

${ }^{9}$ Ibid., pp. 21-22.
} 
movimiento, y solo sucede entre personas, no intermediada por objeto alguno, y por ello revela a un agente (un quién). ${ }^{10}$

A partir de la definición aristotélica del hombre como zoon logon ekhon (animal dotado de la capacidad de hablar, además del zoon politikon), Arendt concluye que la acción siempre va acompañada del discurso. ${ }^{11}$ Lo político, que es lo que sucede "entre hombres" (siendo el pluralismo su condición de posibilidad), presupone a la acción, toda vez que acción y discurso, unidos como "poder", configuran un "espacio de aparición" en que interactúan las personas como agentes, espacio del cual surge la denominada "esfera pública", locus de lo político. ${ }^{12}$

Pues bien, si la acción es un comienzo, que incluso tiene el potencial milagroso de redimir al mundo corrupto, una de sus expresiones más importantes es la natalidad. ${ }^{13}$ Mediante la acción de nacer el recién llegado ingresa a un "mundo", esto es, el conjunto de objetos fabricados por el hombre, así como también los asuntos de quienes habitan entre tales objetos. ${ }^{14}$ Pero el recién llegado no conoce este mundo, y por tanto debe ser instruido en él. Tal instrucción debe ser recibida en un espacio intermedio entre el mundo y la privacidad del hogar: la escuela. ${ }^{15}$ Pero a pesar de que la educación prepara para el mundo, y que parte del mundo son los asuntos que ocurren entre los seres humanos, es decir, la política, Arendt advierte que la educación no tiene una incidencia directamente política, sino que es más bien su presupuesto. La política discurre sobre la base de que las personas están ya educadas. ${ }^{16}$

Ahora bien, Arendt subraya que la educación es la instrucción para la inserción en un mundo, y no en el mero proceso de la vida, pues si de lo último se tratase bastaría solo con entrenar al recién llegado en la sobrevivencia, como hacen los animales. ${ }^{17}$ En otras palabras, la educación no debería estar orientada al perfeccionamiento de la labor, cuya actividad rectora es el consumo. ${ }^{18}$

Sin embargo, la educación económica se orienta al consumo. Esto se explica porque tras un breve reinado del homo faber a partir de la inventiva renacentista, el animal laborans se instaló en la época moderna como máximo

\footnotetext{
${ }^{10}$ Ibid., pp. 21; 38; 100; 157; 200-204.

11 Aristóteles: La Política, Madrid, España, Alba, 2002, p.29. Arendt, Hannah: La condición... (nota 8), p. 39.

12 Ibid., p. 221; Arendt, Hannah: ¿Qué es política?, Barcelona, España, Paidós, 1997, pp. 45-46. Véase también Mouffe, Chantal: El retorno de lo político, Barcelona, España, Paidós, 1999, p. 14.

Arendt, Hannah: La condición... (nota 8) pp. 221-223.

${ }^{13}$ Ibid., pp. 202; 266.

${ }^{14}$ Ibid., p. 62.

15 Arendt, Hannah. "The crisis..." (nota 6) pp. 185; 188.

${ }^{16}$ Ibid., p. 177.

${ }^{17}$ Ibid., p. 185.

18 Arendt, Hannah: La condición... (nota 8) p. 108.
} 
paradigma, siendo la vida (o la "vida corriente" en Charles Taylor, y la "nuda vida" en Giorgio Agamben) y su actividad de consumo elevados a dogma sacramental, no sin ayuda del cristianismo que ve en la vida terrena el primer paso hacia la vida eterna. ${ }^{19}$ De esta manera, la declinación de los estándares de la política, que Leo Strauss y Habermas denuncian en la obra de Maquiavelo y de Hobbes, ha quedado consolidada hoy en la forma de una "educación" que no es más que entrenamiento en las habilidades necesarias para procurar el sustento de nuestra biología. ${ }^{20}$

Habermas (quien adopta íntegramente la antropología de Arendt) denuncia este nefasto tránsito desde la política aristotélica hasta la "filosofía social" de Hobbes, donde lo "social" o societas corresponde a una mera federación por el interés individual para la manutención de la vida, sobre todo desde el hogar u oikos, mientras que lo "político" es lo que sucede entre pares libres e iguales por el bien común de la polis. ${ }^{21}$ La infortunada traducción del zoon politikon como animal social por parte de Santo Tomás de Aquino marca un hito trascendental en esta evolución. ${ }^{22}$

Habermas además hace hincapié en la transmutación de dos categorías fundamentales. De un lado, la antigua phronesis o prudencia ha sido reemplazada por la episteme o conocimiento apodíctico, propio de los tecnócratas. De otro, la praxis o acción, a pesar del intento de Arendt por revitalizarla, ha sido desplazada por la techné o técnica, herramienta del homo faber. La importancia de esto último radica en que mientras la praxis es algo que sucede entre seres humanos, y está por tanto orientada al entendimiento, la techné deja al homo faber solo frente a su creación, por lo que fácilmente su racionalidad deviene estratégica, es decir, manipuladora. ${ }^{23}$

Tras esta revisión estamos en condiciones de avanzar una propuesta en torno a la problemática descrita. La educación, en cuanto proceso de instrucción de un recién llegado para insertarse en un mundo de seres políticos, debe buscar formar un agente que no solo procure su supervivencia ni manipule como objetos a sus pares, sino que los reconozca en cuanto tales mediante una racionalidad comunicativa expresada en las facultades humanas de acción y discurso.

\footnotetext{
19 Taylor, Charles: Fuentes del yo: La construcción de la identidad moderna, Barcelona, España: Paidós, 1996, p. 227-229; Agamben, Giorgio: Homo Sacer. El poder soberano y la nuda vida, I. Valencia, España, Editorial Pre-Textos, 1998, pp. 9-23; Arendt, Hannah: La condición... (nota 8), pp. 330-344.

20 Strauss, Leo. Natural right and history, Chicago, Estados Unidos: The University of Chicago Press, 1953, p. 191.; véase también Habermas, Jürgen: Teoría y praxis. Madrid, España, Tecnos, 1997 , p. 58.

21 Ibid., p. 49.

22 Arendt, Hannah: La condición... (nota 8), pp. 38-39.

${ }^{23}$ Habermas, Jürgen: Teoría y... (nota 20), p. 50. Habermas, Jürgen: Teoría de la acción comunicativa, I. Madrid, España, Taurus, 1981, pp. 122-124. Apel, Karl Otto: Estudios Éticos, México D.F., México, Editorial Fontamara, 2007, p. 36
} 
La educación, en este sentido, deviene verdadera con-formación del educando, por cuanto no se lo instruye solamente en el uso de herramientas (la más sofisticada de las cuales es la información) ni en el consumo, que en definitiva son separables de su persona moral. Se le debe inculcar una manera respetuosa de tratar a sus pares libres e iguales, es decir, una manera que no los conciba como meros objetos producto de una racionalidad estratégica, sino que los considere por medio de una racionalidad comunicativa que propicie el entendimiento entre agentes dotados de la capacidad de acción y discurso. Esta manera de tratar a los pares, que se inculca desde la más temprana niñez del educando, se vuelve parte integrante de su personalidad, es decir, lo con-forma, como una hebra más del entramado que es su biografía o vida cualificada (bios). Tal vida cualificada es necesariamente política, como quiera que se inserte en un relato de lo que sucede "entre personas".

Se sigue de lo anterior que la educación no es un bien de consumo (i.e. un producto que se agota o se destruye tras su uso por parte del destinatario, y que no se vuelve parte de su agencia moral debido a dicha evanescencia), pues no está llamada a servir a la labor orgánica. Tampoco es una herramienta, toda vez que no se puede escindir de quien la vive. Por esto se debe "de-comoditizar" o desmercantilizar la educación, sustrayéndola del dominio de la societas, esto es, del mercado y del afán de lucro, para que pueda ser asignada a cada quien, parafraseando a Fernando Atria, de acuerdo con un criterio de sola pertenencia a la comunidad política. ${ }^{24}$ Como dice Jacques Rancière, la educación es un espacio esencialmente retirado de la vida productiva. ${ }^{25}$ No se trata de un negocio, entendido este como negación del ocio, sino que es una experiencia "ociosa" en el sentido positivo de sustraer a las personas de lo productivo y formarlas, no en el consumir o construir, sino para un trato respetuoso con sus pares humanos libres e iguales. En igual sentido, Michael Walzer sostiene que la educación es una esfera distributiva independiente del mercado, en donde "La finalidad no es reprimir las diferencias sino más bien posponerlas, de modo que los niños aprendan primero a ser ciudadanos $-\mathrm{y}$ trabajadores, gerentes, comerciantes y profesionales después-". ${ }^{26}$

Si como dice Polibio, educar es hacernos ver que somos en plenitud dignos de nuestros ancestros, entonces debemos volver la mirada hacia aquello que buscaban quienes forjaron nuestra república, inspirados en Montesquieu. Debe recuperarse la educación republicana en la virtud, pues virtud es renuncia a uno mismo, y si lo político presupone pluralidad (pues es lo que sucede "entre personas"), solo producto de aquella renuncia virtuosa se puede superar el solipsismo del animal laborans y del homo faber para reconocer la pluralidad en la

\footnotetext{
${ }^{24}$ Atria, Fernando: Mercado y ciudadania en la educación, Santiago, Chile: Flandes Indiano, 2007, pp. $19 ; 80$.

${ }^{25}$ Ruiz, Carlos: op. cit., p. 96.

${ }^{26}$ Walzer, Michael: Las esferas de la Justicia. Una defensa del pluralismo y la igualdad, México D.F., México, FCE, 1997, pp. 209; 214. Véase también Mönckeberg, María Olivia: El negocio de las universidades en Chile, Santiago, Chile, Debate, 2007, p. 119.
} 
REJ - Revista de Estudios de la Justicia - No 18 - Año 2013

agencia de otros. Ello nos habilitará para vivir una vida cualificada en compañía de otros seres políticos.

Pero no solo desde un punto de vista republicano hay necesidad de mejorar la educación, sino también desde uno situado en lo que académicamente se considera como la ribera opuesta, es decir, el liberalismo político. A juicio de John Rawls, "el sistema escolar, sea público o privado, debería ser planeado para derribar las barreras de clase", de manera de dar operatividad al segundo principio de justicia en su formulación de igualdad de oportunidades. ${ }^{27}$

En un país como Chile, en que las progresivas diferencias socioeconómicas amenazan cada día con erosionar la cohesión social y desintegrar el ethos de la comunidad política, la educación pública cumple un rol fundamental como espacio de convergencia de aquello que el mercado ha divorciado. Es por ello que el desiderátum de educación republicana debe ser materializado siempre a lo menos en la educación pública, e idealmente también en la privada (por cierto, sin fines de lucro, como quiera que ya se ha demostrado que la educación no es un bien de consumo), pues la virtud cívica constituye un bien público para la nación que contribuye a preservar la integridad del entramado social y de la comunidad política.

\section{El derecho a la educación}

El derecho a la educación (cuya matriz normativa se compone del art. 26 de la Declaración Universal de los Derechos Humanos; el art. 13 del Pacto Internacional de Derechos Económicos, Sociales y Culturales; los arts. 45 a 50 de la Carta de la OEA; el art. 26 de la Convención Americana sobre Derechos Humanos; y los arts. $5^{\circ}$ inc. $2^{\circ}$ y $19 \mathrm{n}^{\circ} 10$ y n ${ }^{\circ} 11$ de la Constitución Política de la República de Chile) es un "derecho social". ${ }^{28}$ La discusión acerca del carácter de derechos de los derechos sociales ha adoptado entre nosotros la forma del debate entre Fernando Atria y Carlos Bernal Pulido. Bernal Pulido concede a Atria el punto de que "derecho-social" es una contradicción en los términos que designa una ecuación de "egoísmo-solidario", pues reconoce que la solidaridad solo puede existir en grupos como la familia, y que en subsidio de estos debe intervenir el Estado social en la forma del derecho.

Atria acusa que los derechos sociales son en verdad la herramienta de un socialismo claudicante que debe adoptar el lenguaje del derecho burgués para obtener sus reivindicaciones. ${ }^{29}$ En efecto, el derecho subjetivo siempre es una

\footnotetext{
${ }^{27}$ Rawls, John: Teoría de la Justicia, México D.F., México: FCE, 2010, p. 79.

28 Alexy, Robert: Teoría de los Derechos Fundamentales, Madrid, España, Centro de Estudios Políticos y Constitucionales, 2001, p. 482.

29 Atria, Fernando: ¿Existen derechos sociales? <en línea> [Citado 31 agosto 2011]

$<$ www.cervantesvirtual.com/descargaPdf/ existen-derechos-sociales-0/>, pp. 18; 22. Bernal Pulido,
} 
exigencia de un individuo, y como tal no puede fundarse en la solidaridad, sino en un autointerés del acreedor, quien se aleja de la comunidad. ${ }^{30}$

Sin embargo, quien reclama del Estado un derecho social en realidad apela a la comunidad organizada estatalmente. Si desde un punto de vista comunitarista se combate el universalismo del derecho internacional para proteger a la comunidad en la forma del Estado nacional, a fortiori se debe reconocer que también en lo interno el Estado representa a la comunidad institucionalmente organizada. En otras palabras, demandar algo del Estado es requerir algo de la comunidad de la que se forma parte, no distanciarse de ella.

Además, el telos de los derechos sociales no es tanto cultivar un sentimiento de solidaridad entre los ciudadanos, sino más bien brindar condiciones de bienestar a nuestros iguales, para luego sobre esa base de bienestar esperar que la solidaridad brote espontánea y desplace a la ira justa por falta de reconocimiento.

Por último, Atria adopta la definición de Kelsen de los derechos subjetivos "en sentido técnico" para fundar su argumento, sin abundar en la rica discusión doctrinaria que precede a Kelsen. ${ }^{31}$

Tal discusión comienza con la definición por parte de Windscheid del derecho subjetivo como facultad, en un doble sentido. Primero, como derecho a una conducta de otro mandada por el derecho objetivo, mandato que el titular del derecho subjetivo hace suyo. Segundo, como voluntad creadora de derechos. Ambos sentidos confluyen en el concepto de derecho subjetivo como "un poder o señorío de voluntad conferido por el orden jurídico". La debatida "justiciabilidad" o carácter de coercible mediante un procedimiento judicial no pertenece al concepto de derecho subjetivo según Windscheid, aunque reconoce que sin ella se trata de "un derecho imperfecto, pero no por ello es menos derecho". 32

Von Ihering, por su parte, replica a Windscheid que el derecho subjetivo no puede ser un señorío conferido a la voluntad, pues no explica los casos en que los desprovistos de voluntad son titulares de derechos. El verdadero contenido del derecho subjetivo es un "interés jurídicamente protegido", siendo su sustancia la utilidad que reporta a su titular. La justiciabilidad no es parte de esa sustancia, sino más bien es a esta como la "cáscara" es al "fruto". 33

Carlos: Fundamento, concepto y estructura de los derechos sociales. Una critica a "Existen derechos sociales?" de Fernando Atria. <en línea> [Citado 31 agosto 2011] < www.cervantesvirtual.com/.../fundamento-concepto-yestructura-de-los-...>, p. 111.

30 Atria, Fernando: “¿Existen...” (nota 29), pp. 23; 52. Véase también Schmitt, Carl: Teoría de la Constitución. Madrid, España, Alianza, 2001, p. 170.

${ }^{31}$ Dabin, J.: El Derecho Subjetivo. Madrid, España, Editorial Revista de Derecho Privado, 1955, pp. 69-90.

32 Windscheid, Bernard: “Tratado del Derecho de las Pandectas". En: Von Ihering, Rudolph. Dogmática Jurídica, $2^{\mathrm{a}}$ ed., Buenos Aires, Argentina, Losada, 1946, pp. 221-227.

${ }^{33}$ Von Ihering, Rudolph: Dogmática Juridica, $2^{\mathrm{a}}$ ed., Buenos Aires, Argentina, Losada, 1946, pp. 173-181. 
Kelsen tercia en el debate precisando que a todo derecho subjetivo corresponde siempre una obligación correlativa (“derecho reflejo"). La justiciabilidad que el ordenamiento confiere en la forma de un poder jurídico para obtener el cumplimiento de la obligación, es lo que diferencia según Kelsen a un derecho subjetivo de un "derecho subjetivo en sentido técnico". Solo la justiciabilidad confiere tal aspecto técnico. ${ }^{34}$

Como se advierte, ni Windscheid ni Von Ihering, a pesar de todas sus diferencias, reconocen la justiciabilidad como parte de la esencia del concepto de derecho subjetivo. Esta misma línea de pensamiento sigue Alexy, para quien los derechos fundamentales (incluidos los derechos sociales) son derechos subjetivos con independencia de su justiciabilidad. Alexy adopta la idea de Hohfeld de que los derechos subjetivos y sus correlativos deberes son un tipo de relación jurídica, ${ }^{35}$ en particular una relación triádica en que un sujeto $a$ tiene frente a otro sujeto $b$ un derecho G. De esta manera, Alexy concibe a los derechos subjetivos como "posiciones" (del titular frente al obligado). ${ }^{36}$ La justiciabilidad no es parte de la posición por la sencilla razón de que junto al catálogo de derechos fundamentales en las constituciones se suele consagrar una norma especialmente dedicada a obtener ese efecto, ${ }^{37}$ como el art. 19 de la Constitución de Bonn, o los arts. 20 y 21 de la Constitución chilena (que no dispensan protección alguna al derecho a la educación). Por esa misma razón los arts. 577 y 578 del Código Civil chileno señalan expresamente que de los derechos reales y personales "nacen" las acciones reales y personales. Si fueran de la esencia ¿haría falta expresarlas o decir que "nacen" de algo de lo que son parte?

Por lo anterior se puede decir que los derechos sociales, en cuanto posiciones jurídicas, son derechos subjetivos, independiente de su justiciabilidad ante los tribunales. En realidad el problema de la justiciabilidad amenaza con devenir puro realismo jurídico, esto es, considerar al derecho como una predicción de lo que solo los tribunales harán (Holmes). Pero este realismo jurídico en torno a los derechos subjetivos soslaya la "cifra negra" de cumplimientos voluntarios de las obligaciones cuya ocurrencia jamás llega a conocimiento de los tribunales, los cuales pueden ser llamados con propiedad jurídicos, en la medida en que concurra una aceptación del "punto de vista interno" de las reglas que los ordenan. ${ }^{38}$ Esta aceptación tiene que darse, según Hart, a lo menos en los funcionarios y puede que exista entre los ciudadanos, lo que sin duda es deseable para evitar una "nación de borregos". 39

\footnotetext{
${ }^{34}$ Kelsen, Hans: Teoría pura del derecho, México D.F., México, UNAM, 1982, pp. 138-157.

${ }^{35}$ Hohfeld, W.N.: Conceptos jurídicos fundamentales, México D.F., México, Fontamara, 1991, p. 47.

36 Alexy, Robert: op. cit., p. 178.

${ }^{37}$ Ibid., p. 182.

${ }^{38}$ Hart, H.L.A.: El concepto de derecho, Buenos Aires, Argentina: Abeledo Perrot, 1998, pp. 2; 71; 111

${ }^{39}$ Ibid., p. 146.
} 
Pues bien, aclarado el status de los derechos sociales como derechos subjetivos, quisiera para terminar verter algo de vino nuevo en odres viejos, mediante una nueva clasificación tentativa de los derechos fundamentales que se acomode a la conocida bipartición entre derechos civiles y políticos o de "primera generación", y derechos sociales o de "segunda generación", todo esto con la finalidad de determinar el rol del Estado, que es el obligado en la posición jurídica. $^{40}$

Al igual que Stephen Holmes y Cass Sunstein, Víctor Abramovich ha sostenido que las diferencias entre estas generaciones de derechos son solo de grado, pues en ambos casos se imponen obligaciones positivas y negativas para el Estado, si bien reconoce que los derechos sociales se identifican mejor por las obligaciones positivas que demandan. ${ }^{41}$ Esto quiere decir que en los derechos civiles y políticos el Estado en principio se abstiene (o no tiene un amplio "campo de acción" según Alexy), ${ }^{42}$ dejando a veces de abstenerse en mayor o menor medida, mientras que en los derechos sociales el Estado en principio interviene (con un amplio "campo de acción"), dejando a veces de intervenir en mayor o menor medida. Como se advierte, la actuación positiva del Estado puede ser designada tanto como "mayor intervención" cuanto como "menor abstención". Del mismo modo, la actuación negativa del Estado puede traducirse como "mayor abstención” y como "menor intervención".

Pues bien, basados en la reflexión emprendida en la sección anterior, quisiera reclasificar los derechos fundamentales como "derechos de nuda vida" y "derechos de vida cualificada", según si estén orientados, respectivamente, a la preservación de la labor orgánica (como el derecho a la vida, a la salud, a la propiedad, al trabajo, al medio ambiente libre de contaminación, a la vivienda, etc.), o al desarrollo de una forma de vida directamente política en el sentido de lo que sucede "entre personas" (como la libertades de conciencia, de expresión, de enseñanza, el derecho a voto, a postular a cargos de elección popular, a la igualdad ante la ley, el debido proceso, a participar de la vida cultural, etc.).

Como se advierte, tanto en los derechos civiles y políticos como en los derechos sociales se encuentran derechos de nuda vida y de vida cualificada. Es decir, la nueva clasificación se encuentra entrecruzada con los taxones de la clasificación clásica.

\footnotetext{
40 Alexy, Robert: op. cit., p. 520.

41 Abramovich, Víctor: "Líneas de trabajo en derechos económicos, sociales y culturales: herramientas y aliados". En: Zalaquett, José (coord.). Grupo de reflexión regional. Temas de derechos bumanos en debate, Santiago, Chile: CDH Facultad de Derecho Universidad de Chile e Instituto de Defensa Legal, 2004, p. 25. Véase también Holmes, Stephen y Sunstein, Cass: El costo de los derechos. Por qué la libertad depende de los impuestos, Buenos Aires, Argentina, Siglo XXI Editores, 2011, pp. 55-97.

42 Alexy, Robert: op. cit., p. 447.
} 
La diferencia fundamental, atendido dicho entrecruzamiento, radica en que el Estado debe intervenir más (si hablamos de la segunda generación de derechos) o abstenerse menos (en la primera generación) en el aseguramiento de los derechos de vida cualificada, mientras que puede intervenir menos o abstenerse más en los de nuda vida, entregando en buena parte su satisfacción al mercado (por ejemplo, con el Plan Auge en la salud, cuya lógica de vouchers o "cupones" resultaría, no obstante, inaplicable en la educación, por las razones ya aducidas sobre la erradicación del afán de lucro en este derecho). La mayor presencia del Estado en los derechos de vida cualificada se debe a que es la institución política moderna por antonomasia, y por tanto permite el desarrollo de la vida buena y la virtud cívica.

Lo que se propone es que el derecho a la educación es un derecho social de vida cualificada, y por tanto el Estado debe intervenir más en su aseguramiento, fortaleciendo la educación pública en todos sus niveles, velando por la calidad de la educación (pública y privada) y evitando que el mercado sea el distribuidor de la formación en una virtud cívica que nos habilite para el reconocimiento mutuo como libres e iguales. En cuanto a la libertad de enseñanza, en tanto derecho civil y político de vida cualificada, el Estado debe abstenerse menos, estableciendo exenciones tributarias y otras medidas normativas positivas.

\section{Conclusión}

La educación no debe ser concebida como el mero entrenamiento en habilidades de sobrevivencia orientadas a la preservación de la nuda vida, ni como la capacitación en el uso de herramientas para la producción, sino como un verdadero ejercicio de con-formación del educando, en que lo aprendido se torna parte integrante de este como sujeto de la acción, es decir, como zoon politikon y no como animal laborans u homo faber.

La educación consiste en un espacio ocioso esencialmente no productivo en que se forma al recién llegado en la virtud o renuncia a uno mismo, posibilitadora de la pluralidad y de lo político. Esta pluralidad demanda formar al educando en el trato con sus pares como libres e iguales, capaces de mutuo entendimiento en virtud de sus dotes de acción y discurso.

En cuanto derecho, a pesar de su falta de justiciabilidad en el art. 20 de la Constitución chilena, el derecho a la educación es un derecho subjetivo en el sentido histórico (que no técnico) del término, a la luz de la rica discusión doctrinaria que se ha desarrollado en torno al concepto de derecho subjetivo.

Además, en la nueva clasificación propuesta, dicho derecho se ubica entre los derechos sociales de vida cualificada, por cuanto está orientado hacia la relación entre personas, es decir, hacia lo propiamente político, lo que trae como consecuencia la necesidad de una mayor intervención del Estado en el 
Lobo - Derecho a la educación: sobre la con-formación para una vida cualificada

fortalecimiento de la educación pública y en el control de la calidad de la educación en general.

Las manifestaciones estudiantiles en Chile, que sirven de pábulo a esta reflexión, demuestran que una propuesta educativa orientada hacia la virtud para vivir una vida cualificada no caerá en tierra estéril, por cuanto los estudiantes movilizados ya han demostrado la virtud cívica de que son capaces por sí mismos. Pues si virtud significa renuncia a uno mismo, todos quienes están dispuestos a arriesgar la pérdida de su año académico e incluso su vida e integridad física en una huelga de hambre, sabiendo que los beneficios de su acción no se percibirán sino dentro de mucho y para futuras generaciones, entonces se puede decir que no solo "los granujas", como decía Goethe, "son dueños de la calle", sino también los virtuosos. Si hay alguien que merece ser llamado digno de los fundadores de la República, son ellos. Solo hay que imaginar qué tipo de ciudadanía robusta se formaría si con ese tipo de pupilos el Estado asumiera su rol educador. 
REJ - Revista de Estudios de la Justicia - No 18 - Año 2013

\section{BIBLIOGRAFÍA}

* ABRAMOVICH, Víctor: "Líneas de trabajo en derechos económicos, sociales y culturales: herramientas y aliados", en ZALAQUETT, José (coord.). Grupo de reflexión regional. Temas de derechos humanos en debate. Santiago, Chile: CDH Facultad de Derecho Universidad de Chile e Instituto de Defensa Legal, 2004.

* AgAmBEN, Giorgio: Homo Sacer. El poder soberano y la nuda vida. I. Valencia, España, Editorial Pre-Textos, 1998.

* ALEXY, Robert: Teoría de los Derechos Fundamentales. Madrid, España, Centro de Estudios Políticos y Constitucionales, 2001.

* APEL, Karl Otto: Estudios Éticos. México D.F., México, Editorial Fontamara, 2007.

* ARENDT, Hannah. ¿Qué es política? Barcelona, España, Paidós, 1997.

* La condición bumana. Buenos Aires, Paidós, 2005.

* _The crisis in education", en Between past and future. Eight exercises in political thought. Nueva York, Estados Unidos, The Viking Press, 1961.

* ARISTÓteles: La Política. Madrid, España, Alba, 2002.

* ATRIA, Fernando: “¿Existen derechos sociales?” <en línea> [Citado 31 agosto 2011] $<$ wnw.cervantesvirtual.com/ descargaPdf/ existen-derechos-sociales-0/>

* Mercado y ciudadanía en la educación. Santiago, Chile, Flandes Indiano, 2007.

* BERNAL PULIDO, Carlos: Fundamento, concepto y estructura de los derechos sociales. Una crítica a "Existen derechos sociales?" de Fernando Atria <en línea> [Citado 31 agosto 2011] $<$ wnw.cervantesvirtual.com /.../fundamento-concepto-y-estructura-de-los-... $>$

* DABIN, J. El Derecho Subjetivo. Madrid, España, Editorial Revista de Derecho Privado, 1955.

* HABERMAS, Jürgen: Teoría de la acción comunicativa, I. Madrid, España, Taurus, 1981.

* Teoría y praxis. Madrid, España, Tecnos, 1997.

* HART, H.L.A: El concepto de derecho. Buenos Aires, Argentina, Abeledo Perrot, 1998.

* HOHFELD, W.N.: Conceptos jurídicos fundamentales. México D.F., México, Fontamara, 1991.

* HOLMES, Stephen y SUNSTEIN, Cass: El costo de los derechos. Por qué la libertad depende de los impuestos. Buenos Aires, Argentina, Siglo XXI Editores, 2011.

* HORWITZ, Robert John Dewey: en STRAUSS, Leo y CROPSEY, Joseph (comp.). Historia de la filosofía politica. $3^{\mathrm{a}}$ ed., México D.F., México, FCE, 2006.

* KELSEN, Hans: Teoría pura del derecho. México D.F., México, UNAM, 1982.

* MÖNCKEBERG, María Olivia: El negocio de las universidades en Chile. Santiago, Chile, Debate, 2007.

* MONTESQUiEU, Charles: Del espiritu de las leyes. Madrid, España, Tecnos, 2000.

* MOUFFE, Chantal: El retorno de lo politico. Barcelona, España, Paidós, 1999.

* RAWLS, John: Teoría de la Justicia. México D.F., México, FCE, 2010.

* RUIZ, Carlos: De la República al mercado. Ideas educacionales y politica en Chile. Santiago, Chile, LOM, 2010.

* SCHMITT, Carl: Teoría de la Constitución. Madrid, España, Alianza, 2001.

* STRAUSS, Leo: Natural right and history. Chicago, Estados Unidos, The University of Chicago Press, 1953.

* TAYLOR, Charles: Fuentes del yo: La construcción de la identidad moderna. Barcelona, España, Paidós, 1996.

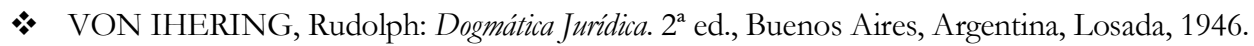

* WALZER, Michael: Las esferas de la Justicia. Una defensa del pluralismo y la igualdad. México D.F., México, FCE, 1997.

* WINDSCHEID, Bernard: "Tratado del Derecho de las Pandectas", en VON IHERING, Rudolph. Dogmática Jurídica. $2^{a}$ ed., Buenos Aires, Argentina, Losada, 1946. 